\title{
K15 NEMATIC PHASE LIQUID CRYSTAL MATERIAL BASED DOUBLE-DIPOLE RECONFIGURABLE ANTENNA
}

\author{
B. T. P. Madhav, D. Sreenivas Rao, K. Supraja, A. Tejaswini, A. Phanikumar, \\ A. Nagarjunareddy, R. Sai Prakash and A. N. Meena Kumari \\ Department of ECE, K L University, AP, India \\ *E-mail: btpmadhav@kluniversity.in
}

\begin{abstract}
In this paper, the study is carried out on frequency reconfigurable antenna for wireless applications. The tuning of the antenna is done by changing its effective electrical length. The proposed antenna structure consists of two dipoles. By connecting and disconnecting the slots, lengths of the coplanar strips of the dipoles can be varied .Therefore antenna can be operated in both multi-band and wideband frequencies. The results plotted after simulations propose that the designed antenna is capable of maintaining its operating frequency over a range of $1.5 \mathrm{GHz}$ to $8 \mathrm{GHz}$. This frequency reconfigurability implemented symmetrically on the two dipoles enhances the overall gain of the antenna from $3 \mathrm{~dB}$ to $5 \mathrm{~dB}$ at multiple bands over different combinations mentioned in this paper. Keywords: Microstrip patch antenna, Dual Frequency, Reconfigurable, Liquid Crystals.
\end{abstract}

(C) RASĀYAN. All rights reserved

\section{INTRODUCTION}

Currently, there is a wide development in a wireless communication system that demands to access of various frequency bands using a single antenna. Here, reconfigurability comes into existence with the capacity to change the operating characteristics through electrical and mechanical parameters. Reconfigurable antennas exhibit low profile and light weight properties. ${ }^{1,2}$ In order to alter the operating frequency, reconfigurable antennas should be able to change operating frequency, impedance bandwidths, and radiation pattern. ${ }^{3}$ Multiple functions need to be performed on a single convergence. ${ }^{4}$ A single antenna is used in wireless devices such as cellular telephone, laptops and other wireless devices. These antennas are usually monopole or micro strip antenna based which are having the capability to access multiple frequencies. Some packages may require two or more antennas on small devices for the reception and Transmission of signal but the use of only one antenna for several needs can be served through frequency reconfigurability. The restrictions like size, cost, power transmission from device to the base station is very weak in a bidirectional communication system. Moreover, these devices are often used in harsh electromagnetic conditions, which decrease the performance of the antenna. In such situation, the reconfigurable antenna provides many advantages. By changing the length of the dipole operating frequencies can be altered. Microstrip patch antennas are a suitable antenna for the implementation of reconfigurable antennas. In recent years, reconfigurable antennas have received significant attention for their applications in communications, electronic surveillance, and countermeasures by adapting their properties to achieve selectivity in frequency, bandwidth, polarization, and gain.

Frequency reconfigurability of an antenna is the capability of the antenna to radiate at different frequencies suitable for different applications. ${ }^{5}$ In the proposed antenna, by changing the length of the strips provided in the antenna frequency reconfigurability can be done effectively. ${ }^{6}$ The design consists of different combinations in which the length of the Coplanar strips is varied such that a peak gain of 4.609 $\mathrm{dB}$ is obtained in multi band range In addition to this, other combinations $0100,1000,1100,1010$ of the lengths are considered which are operated in wide band with Peak gain of $4.1 \mathrm{~dB}, 3.8 \mathrm{~dB}, 5.0 \mathrm{~dB}, 4.1 \mathrm{~dB}$ respectively that supports different applications such as Wi-Fi, Wi-Max, Bluetooth. 


\section{EXPERIMENTAL}

Depending on the temperature, liquid crystal (LC) phase exists in between crystalline solid and an isotropic liquid. In this state, the material can flow like a liquid but at the same time, molecules have orientation order. A typical LC molecule has a rod like a shape as shown in Fig.-1. The size of the molecule is typically is few nanometres. This shape anisotropy causes anisotropy in terms of dielectric constant. ${ }^{6}$
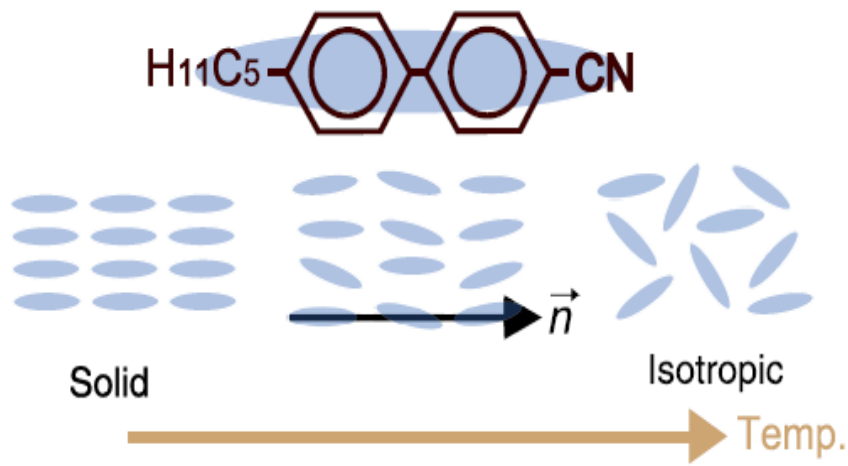

Fig.-1: Typical Liquid Crystal Molecule and its temperature dependency

Cross section of K15 Liquid Crystal based molecule orientation with bias voltage is shown in Figure-2.

Depending on the RF field distribution and $\vec{n}$, LCs feature anisotropic electrical properties. The thin polyimide film is coated on the inner surface of the substrates to orient the LC molecules parallel to the surface initially. ${ }^{7,8}$

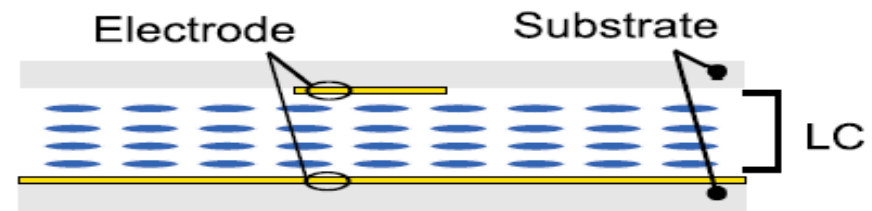

(a)
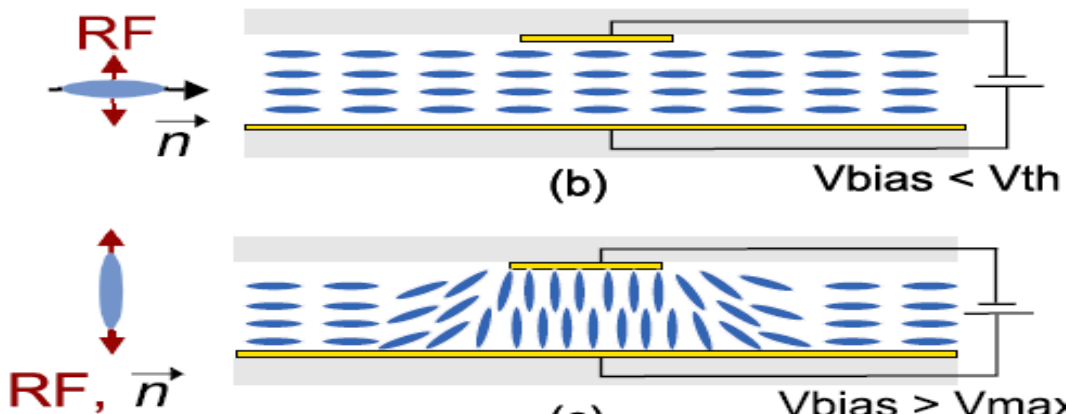

(c)

Vbias > Vmax

Fig.-2: LC Molecules orientation with applied bias voltage

At this level, the RF field distribution is perpendicular to the director $\vec{n}$ as shown in the Fig.-2 and the relative permittivity and loss tangent along the short axes are effective. The orientation of the molecules will be same if the applied bias voltage is less than the threshold voltage. If applied voltage exceeds certain voltage Vmax then all molecules will be aligned parallel to the bias voltage. When a voltage is released, then molecules return to the initial state due to the polyimide film. Required time for this process is defined as switching time which depends on LC material, its thickness, temperature and its orientation mechanism. ${ }^{9}{ }^{10}$ All other states between $\varepsilon \|$ and $\varepsilon \perp$ equivalently continuous tunability can be achieved by varying the applied voltage between the threshold voltage and Vmax. A general characteristic of LC that is dielectric constant and loss tangent versus bias voltage is plotted in Fig.-3. 
RASĀYAN J. Chem.

Vol. 10 | No. 3 |866 - 872 | July - September | 2017

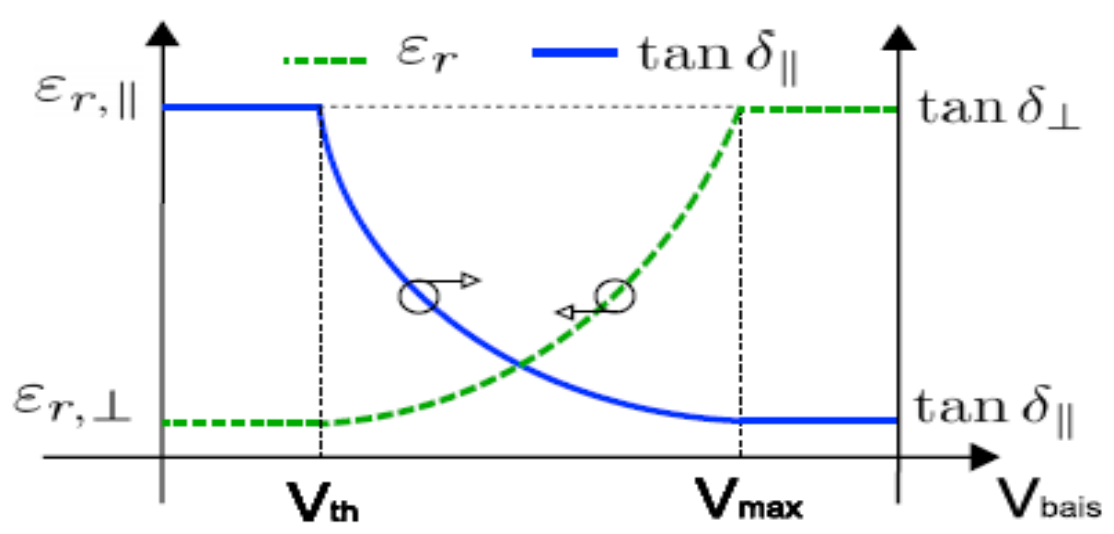

Fig.-3: $\varepsilon_{\mathrm{r}}$ and $\tan \delta$ characteristics of LC material Vs bias voltage

Nematic phase state liquid crystal is a non linear dielectric material in which the dielectric constant can be changed between two extreme states that are described by the orientation of the liquid crystal molecules, either parallel or perpendicular to the excited RF field. ${ }^{11,12}$ The effective dielectric anisotropy can be defined as:

$\Delta \varepsilon=\varepsilon \| l-\varepsilon \perp$

Where $\Delta \varepsilon=$ Dielectric anisotropy

$\varepsilon \|=$ LC Permittivity with DC voltage

$\varepsilon \perp=$ LC Permittivity without DC voltage

Instead of placing a microstrip line on the top substrate, microstrip patches can be realized as antenna elements. Reconfigurable reflect arrays also can be designed based on the principle of variable patch dimensions. Instead of changing the dimensions of the metallized patch, dielectric properties of LC under the patches are tuned with a bias voltage. Although all the patches have identical physical dimensions, they have different electrical properties. This results in different backscattered phases. Beam forming is possible as different patch lengths from a feed to the patches are compensated by the preadjusted phases of the patches.

Our intention is to use the liquid crystal and liquid crystal polymer based materials as substrate materials in the design of microstrip patch antennas. By looking at the basic operating mechanism in terms of dielectric anisotropy with a change in bias voltage between two electrodes, we can tune the antenna to our desired frequency and digital controllability will be in our hand. Liquid crystal substrate material can be attained with LC cavity by placing spherical spacers with a small diameter between two substrates. Although antenna consists of three dielectric layers which are a top substrate, LC layer and bottom substrate the thickness should be maintained low to attain compactness in size.

\section{Antenna Geometry}

An F- shaped antenna which operates at different frequency bands is designed by including strips of different lengths. The antenna consists of two elements, one is on the front side of the substrate and the other is fabricated on the backside of the substrate. The F shaped antenna is constructed by using FR4 epoxy substrate whereFR4 stands for flame retardant which can be used as a perfect electrical insulator possessing considerable mechanical strength. The relative permittivity of FR4 $\left(\varepsilon_{r}\right)$ is 4.4 , loss tangent is 0.02 and with the thickness of $0.8 \mathrm{~mm}$. The feeding technique used here is microstrip feed line technique.

$$
\frac{w}{d}=\left\{\frac{8 e^{A}}{e^{2 A-2}}\right\} \text { for } \frac{w}{d}<2
$$




$$
\begin{aligned}
& \frac{w}{d}=\frac{2}{\pi}\left[B-1-\ln (2 B-1)+\frac{\epsilon_{r}-1}{2 \epsilon_{r}}\left\{\ln (B-1)+0.39-\frac{0.61}{\epsilon_{r}}\right\}\right] \text { for } \frac{w}{d}>2 \\
& \mathrm{~A}=\frac{Z_{0}}{60} \sqrt{\frac{\epsilon_{r}+1}{2}}+\frac{\epsilon_{r}-1}{\epsilon_{r}+1}\left(0.23+\frac{0.11}{\epsilon_{r}}\right) \\
& \mathrm{B}=\frac{377 \pi}{2 Z_{0} \sqrt{\epsilon_{r}}}
\end{aligned}
$$

Where, ' $\epsilon_{r}$ ' is the dielectric constant of the substrate by which the width ' $\mathrm{W}$ ' and thickness $\mathrm{d}$ of the substrate can be calculated by substituting the respective values in the above formulae. The schematic of the proposed antenna is shown as follows having eight Co planar strips (CPS) separated by slot width S. By varying the slot width $S$ present between the different strips, different combinations of Lengths can be obtained which alters the frequency of Operation accordingly.

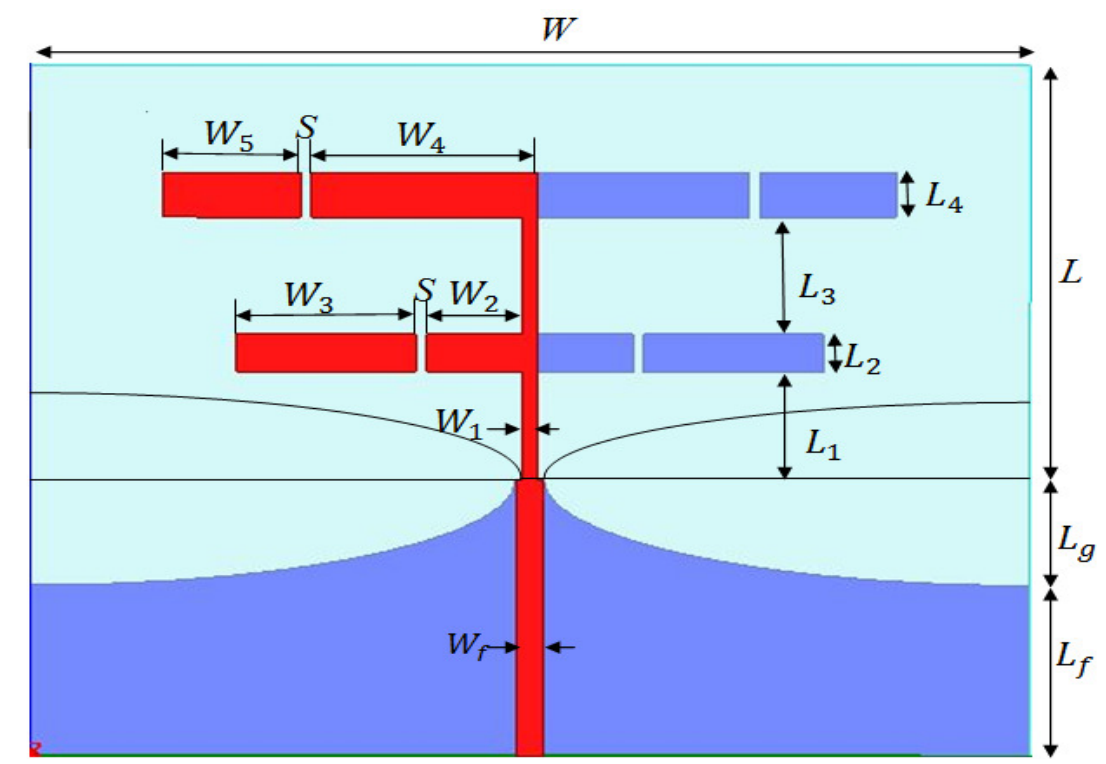

Fig.-4: F-Shaped antenna

'W' is the width of the substrate and it is $93.5 \mathrm{~mm}$ and Length is $\mathrm{L}+\mathrm{L}_{\mathrm{g}}+\mathrm{L}_{\mathrm{f}}$ in which $L_{g}+L_{f}$ gives the length of the feed line and partial ground structure, where ' $L_{g}$ ' is the length of the semi minor axis of the ellipse and ' $L_{f}$ ' is the length of the ground. The value of $L_{g}+L_{f}$ is $30.86 \mathrm{~mm}$ and the value of $\mathrm{L}=$ $46.3 \mathrm{~mm}$.

Table-1: Antenna Dimensions

\begin{tabular}{c|c|c|c|c|c|c|c|c|c|c}
\hline$W_{f}$ & $W_{1}$ & $W_{2}$ & $W_{3}$ & $W_{4}$ & $W_{5}$ & $L_{1}$ & $L_{2}$ & $L_{3}$ & $L_{4}$ & $S$ \\
\hline $2.6 \mathrm{~mm}$ & $1.3 \mathrm{~mm}$ & $9 \mathrm{~mm}$ & $16.8 \mathrm{~mm}$ & $19.8 \mathrm{~mm}$ & $12.8 \mathrm{~mm}$ & $12 \mathrm{~mm}$ & $4.3 \mathrm{~mm}$ & $13 \mathrm{~mm}$ & $5 \mathrm{~mm}$ & $1 \mathrm{~mm}$ \\
\hline
\end{tabular}

The variables that are tabulated in above table which specifies different dimensions of the design with width of the feed line $\mathrm{W}_{1}, \mathrm{~W}_{2}$ and $\mathrm{W}_{3}$ are the widths of the Coplanar strips(CPS)present in the first arm and ' $W_{4}$ ', ' $W_{5}$ ' represents the width of the strips present in the second arm of the dipole. ' $W_{f}$ ' is the width of feeding element, ' $L_{1}$ ' is the separation between the feed line and first arm. ' $L_{2}$ ' specifies the length of the first arm of the dipole. ' $L_{3}$ ' is the separation between the first arm and second arm of dipole 
and ' $L_{4}$ ' is the length of the second arm of the dipole. ' $\mathrm{S}$ ' describes the horizontal separation between the two Coplanar strips (CPS).

\section{RESULTS AND DISCUSSION}

The rectangular partial ground plane defects with a quarter elliptical slots on the either side of the feed line. The design consists of four slots, two slots on the front side and another two slots on the back side of the substrate. By connecting and disconnecting the conducting strips in the slots, ON and OFF conditions are considered and thus by varying the lengths of the antenna elements, sixteen combinations can be obtained which affects the length of the elements. By connecting coplanar strips (CPS) to the slots, ON case can be obtained which are considered as $\mathbf{1}$ and similarly by disconnecting the coplanar strip (CPS), OFF case can be obtained and considered as $\mathbf{0}$. Different combinations of Length of coplanar strips results in significant change in Operating frequency and peak gain which are tabulated in the following Table-2.

Table-2: Antenna parameters with different combinations of coplanar strips

\begin{tabular}{|c|c|c|c|}
\hline Model & combinations & $\begin{array}{c}\text { Operating frequency } \\
(\mathrm{GHz})\end{array}$ & Peak gain $(\mathrm{dB})$ \\
\hline \multirow[t]{3}{*}{1} & \multirow[t]{3}{*}{0010} & $2.18-2.85$ & \multirow[t]{3}{*}{3.3826} \\
\hline & & $3.35-3.53$ & \\
\hline & & $5.58-5.81$ & \\
\hline \multirow[t]{3}{*}{2} & \multirow[t]{3}{*}{0100} & $2-3.05$ & \multirow[t]{3}{*}{4.1007} \\
\hline & & $3.22-3.60$ & \\
\hline & & $7.01-7.64$ & \\
\hline \multirow[t]{5}{*}{3} & \multirow[t]{5}{*}{0101} & $1.53-1.66$ & \multirow[t]{5}{*}{3.3813} \\
\hline & & $2.3-2.65$ & \\
\hline & & $3.35-3.58$ & \\
\hline & & $7.07-7.5$ & \\
\hline & & $7.73-8.07$ & \\
\hline \multirow[t]{3}{*}{4} & \multirow[t]{3}{*}{1000} & $2.20-3.01$ & \multirow[t]{3}{*}{3.8333} \\
\hline & & $3.23-3.55$ & \\
\hline & & $7.02-7.50$ & \\
\hline \multirow[t]{3}{*}{5} & \multirow[t]{3}{*}{1010} & $2.19-2.91$ & \multirow[t]{3}{*}{4.1867} \\
\hline & & $3.30-3.50$ & \\
\hline & & $7.014-7.37$ & \\
\hline \multirow[t]{2}{*}{6} & \multirow[t]{2}{*}{1011} & $1.72-1.83$ & \multirow[t]{2}{*}{4.6902} \\
\hline & & $7.09-7.41$ & \\
\hline \multirow[t]{3}{*}{7} & \multirow[t]{3}{*}{1100} & $2.29-3.54$ & \multirow[t]{3}{*}{5.0745} \\
\hline & & $7.06-7.53$ & \\
\hline & & $7.94-8.11$ & \\
\hline \multirow[t]{3}{*}{8} & \multirow[t]{3}{*}{1101} & $1.51-1.65$ & \multirow[t]{3}{*}{2.4050} \\
\hline & & $3.34-3.53$ & \\
\hline & & $7.04-7.47$ & \\
\hline
\end{tabular}

From the above table it is evident that by changing the length of the Coplanar strips(CPS), different combinations are obtained in which some of the combinations resulting in wideband and the others operate at multi band frequencies resulting in peak gain variation.

The graph ( Fig.-5) of return loss $\left(S_{11}\right.$ ) for four models 2,4,5,7Where model-2 operates at three bands of frequencies 2-3.05 GHz, 3.22-3.60 GHz, 7.01-7.64 GHz which is used exclusively for Wi-Fi IEEE $802.11 \mathrm{~b} / \mathrm{g} / \mathrm{n}$. Model-4 operates at a wide range of frequencies $2.20-3.01 \mathrm{GHz}, 3.23-3.55 \mathrm{GHz}, 7.02-$ 7.5GHzthat can be used for both WiMAX IEEE 802.16 and Bluetooth IEEE 802.15 applications. Model 4 and model 6 operates in different bands and a minimum return loss of $-35 \mathrm{~dB}$ can be achieved with narrow band widths of 2.20-3.01 GHz and 3.23-3.55 GHz. Model 2 and model 7 works for wideband operating 
RASĀYAN J. Chem.

Vol. 10 | No. 3 |866- 872 | July - September | 2017

frequencies and they are 2.29-3.54GHz, 7.06-7.53 GHz, and 7.94-8.11 GHz which can be utilized for WiMAX and Bluetooth applications. In model-5, it operates for larger frequency bands in the range 2.192.91GHz, 3.30-3.50 GHz, 7.014-7.37 GHz which is used to operate for both Wi-Fi IEEE $802.11 \mathrm{~b} / \mathrm{g} / \mathrm{n}$ and WiMAX IEEE 802.16.

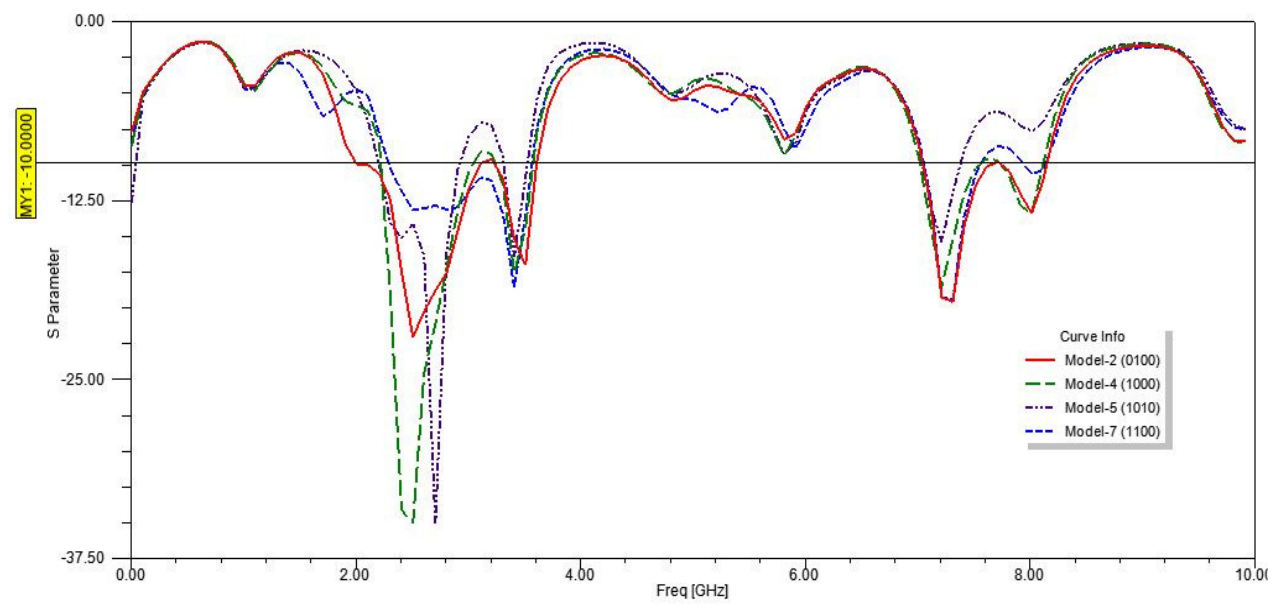

Fig.-5: S Parameter plot for Wideband combinations

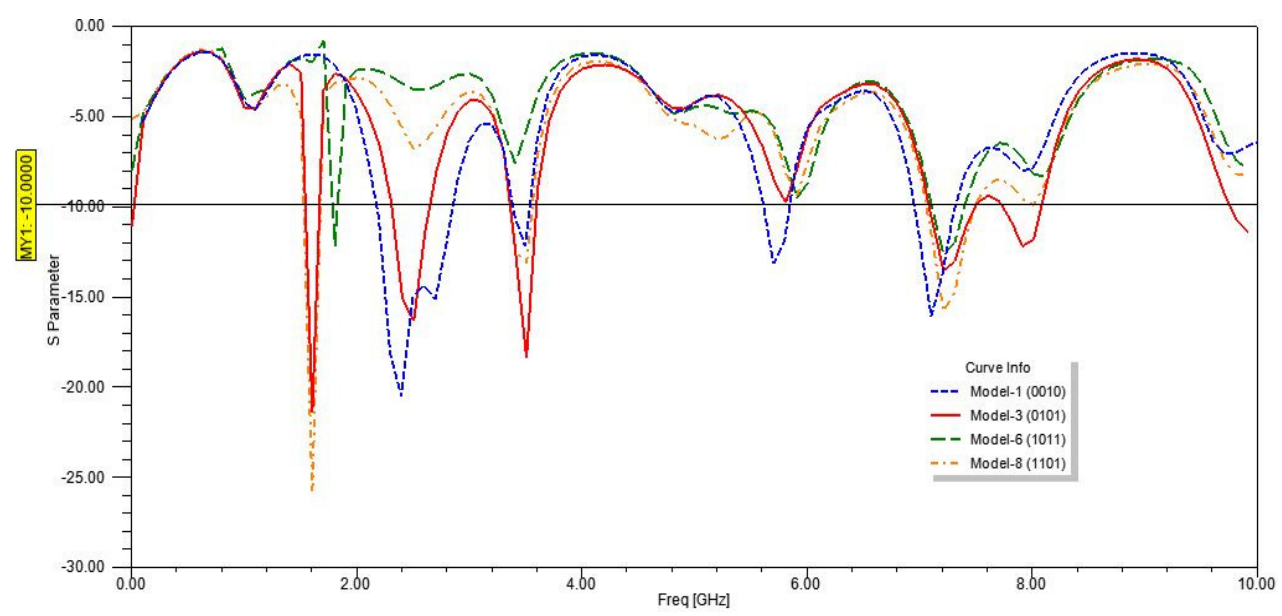

Fig.-6: S Parameter plot for Multiband combinations

The above graph (Fig.-6) of return loss (S11) is depicted for four models 1, 3, 6, 8. The model-6(1011) offers 2 operating bands of $1.72-1.83 \mathrm{GHz}, 7.09-7.41 \mathrm{GHz}$ with a gain of $4.6902 \mathrm{~dB}$. The model-8 (1101) operates in three bands $1.51-1.65 \mathrm{GHz}, 3.34-3.53 \mathrm{GHz}, 7.04-7.47 \mathrm{GHz}$ that can use exclusively for GPS applications with a gain of $2.4050 \mathrm{~dB}$. Where model-1(0010) gives good return loss values at bands 2.18 2.85 GHz, 3.35-3.53 GHz, 5.58-5.81 GHz with a gain of $3.3826 \mathrm{~dB}$ used in $3 \mathrm{G}$ Cellular systems like PCS 1900.There is a significant increase in the band width of model 1 when compared to model 3 . The model$3(0101)$ operates in 5 bands of $1.53-1.66 \mathrm{GHz}, 2.3-2.65 \mathrm{GHz}$ and $3.35-3.58 \mathrm{GHz}, 7.07-7.5 \mathrm{GHz}, 7.73-8.07$ $\mathrm{GHz}$ with a gain of $3.3813 \mathrm{~dB}$ which is offered for $3 \mathrm{G}$ application of DCS 1800 .

VSWR indicates the power reflected from the antenna which must be as small as possible. Here the combination 0100 has minimum losses over a wide band of $1.9-3.6 \mathrm{GHz}$ and 0101 with low loss at five different frequencies of $1.6 \mathrm{GHz}, 2.4 \mathrm{GHz}, 3.5 \mathrm{GHz}, 7 \mathrm{GHz}$ and $8 \mathrm{GHz}$ produces multi-band applications. All the four models have a common frequency of $7 \mathrm{GHz}-8 \mathrm{GHz}$ with less loss. Among all the combinations 1100 got max peak gain of $5.0745 \mathrm{~dB}$. After reconfiguration of the antenna into mode 1011 offers a gain of $4.69 \mathrm{~dB}$ at $7.2 \mathrm{GHz}$. The combinations 0100 and 1010 obtain similar peak gain of $4.1 \mathrm{~dB}$ by operating them at a frequency of $2.5 \mathrm{GHz}$ and $2.7 \mathrm{GHz}$ respectively. 
RASĀYAN J. Chem.

Vol. 10 | No. 3 |866 - 872 | July - September | 2017

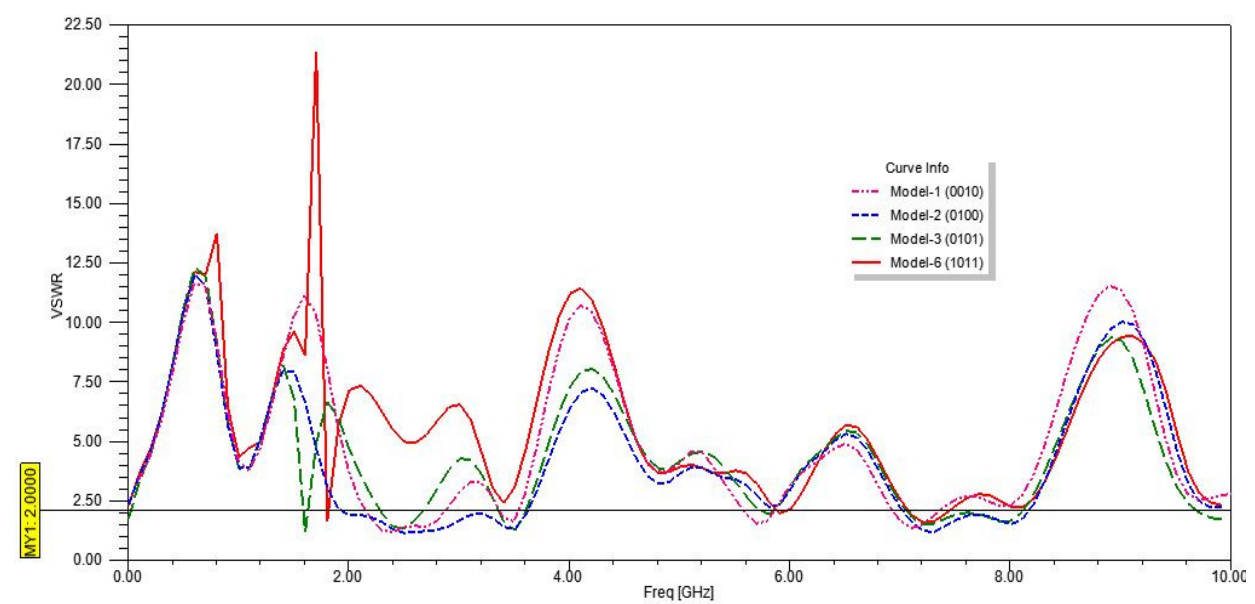

Fig.-7: VSWR plot for different combinations

CONCLUSION

A frequency re configurable double-dipole antenna is designed for wireless applications. The proposed antenna structure offers multi-band and wideband modes. The simulated results indicate that the antenna is capable of shifting its operating frequency over a bandwidth from $1 \mathrm{GHz}$ to $8 \mathrm{GHz}$ with the radiation pattern essentially unaffected by the frequency tuning. The antenna offers a good matching over multiband and wideband frequencies with minimal losses and improved gain compare to the other structures. The parameters such as return loss, VSWR, radiation pattern and gain are verified.

\section{ACKNOWLEDGEMENT}

Authors like to express their sincere thanks to the department of ECE and management of K L University for the encouragement during this work. We thank DST for the grant ECR/2016/000569, SR/FST/ETI$316 / 2012$, and EEQ/2016/000604.

\section{REFERENCES}

1. Abdelnasser Eldek, Abubaker Abdallah and Mahmoud Manzoul, Wireless Engineering and Technology, 2(2), 60 (2011).

2. Dimitrios Peroulis,Kamal Sarabandi and Linda P. B. Katehi, IEEE Transactions on Antenna and wave Propagations, 53(2), 645 (2005)

3. A. A. Eldek, Progress In Electromagnetics Research, PIER 59 (2), 1 (2006)

4. S. V. Shynu, G. Augustin, C. K. Aanandan, P. Mohanan, and K. Vasudevan, Progress In Electromagnetics Research, PIER 60 (3), 197 (2006).

5. V.G.K.M.Pisipati, B.T.P.Madhav and D.Madhavi Latha, Molecular Crystals \& Liquid Crystals, $\mathbf{5 2 4}$ (2), $166(2010)$

6. V.G.K.M.Pisipati, D.Madhavi Latha, B.T.P.Madhav and P. V. Datta Prasad, Z. Nature forsch, 65a, $335(2010)$

7. B.T.P. Madhav and V.G.K.M. Pisipati, International Journal of Applied Engineering Research, 6(9), 1099 (2011)

8. B. T. P. Madhav, ARPN Journal of Engineering and Applied Sciences, 6(4), 98 ( 2011)

9. B.T.P.Madhav, VGKM Pisipati1 and Habibulla Khan, Journal of Engineering Science and Technology Review, 4(2), 131 (2011).

10. B. T. P. Madhav, V. G. K. M. Pisipati, , D. Madhavi latha and P. V. Dattaprasad, Solid State Phenomena, 181(3), 289 (2012).

11. B.T.P. Madhav, M. Venu Gopala Rao, V.G.K.M. Pisipati, Liquid Crystals, 42(2), 198 (2014).

12. B.T.P Madhav, M. Venu Gopala Rao and V.G.K.M Pisipati, Liquid Crystals Today, 24(2), 38 (2015).

[RJC-1679/2017]

DOUBLE-DIPOLE RECONFIGURABLE ANTENNA 